\title{
Article \\ Impacts of Litter Composition on the Structure and Functional Pathways of Soil Microbial Community during Phyllostachys Edulis Expansion
}

\author{
Huiyun Dong ${ }^{1,2}$, Shuai Shao ${ }^{1,2}$, Chenfei Liang ${ }^{1,2}$, Qiufang $X u^{1,2}$, Junhui Chen ${ }^{1,2}$ and Hua Qin ${ }^{1,2, *}$ (D) \\ 1 State Key Laboratory of Subtropical Silviculture, Zhejiang A\&F University, Lin'an, Hangzhou 311300, China; \\ huiyun.dong@zju.edu.cn (H.D.); shuaishao2019@zafu.edu.cn (S.S.); Liangchenfei@zafu.edu.cn (C.L.); \\ xuqiufang@zafu.edu.cn (Q.X.); junhui@zafu.edu.cn (J.C.) \\ 2 College of Environmental and Resource Sciences, Zhejiang A\&F University, Lin'an, Hangzhou 311300, China \\ * Correspondence: qinhua@zafu.edu.cn
}

Citation: Dong, H.; Shao, S.; Liang, C.; Xu, Q.; Chen, J.; Qin, H. Impacts of Litter Composition on the Structure and Functional Pathways of Soil Microbial Community during Phyllostachys Edulis Expansion. Agronomy 2022, 12, 220. https:// doi.org/10.3390/agronomy12010220

Academic Editor: Andrea Baglieri

Received: 3 December 2021

Accepted: 12 January 2022

Published: 17 January 2022

Publisher's Note: MDPI stays neutral with regard to jurisdictional claims in published maps and institutional affiliations.

Copyright: (c) 2022 by the authors. Licensee MDPI, Basel, Switzerland. This article is an open access article distributed under the terms and conditions of the Creative Commons Attribution (CC BY) license (https:// creativecommons.org/licenses/by/ $4.0 /)$.

\begin{abstract}
Forest ecosystem succession plays an important role in soil microbiota variation, and soil microbes will re-establish ecosystem function after disturbance events. A distinctive disturbance of the expansion of bamboo forest into the surrounding broadleaved ecosystem is the change in litter type input. We conducted a 6-month microcosm experiment to examine the effects of proportional changes in leaf litter composition due to moso bamboo (Phyllostachys edulis) invasion into a broadleaved forest on soil microbial community. A series of mixed litters were prepared with bamboo litter occupying at $0 \%, 33 \%, 50 \%, 67 \%$ and $100 \%$ in proportion (with a decrease in litter carbon $(\mathrm{C}) /$ nitrogen $(\mathrm{N})$ from 36.23 to 31.35), and they were then amended into a broadleaved forest soil at a rate of $1 \%$, respectively. Soil bacterial and fungal communities at different incubation stages were determined by high-throughput sequencing. With the increasing proportion of bamboo litter, the broadleaved forest soil exhibited strong changes in microbiome assembly, including reducing bacteria alpha-diversity, the relative abundance of Acidobacteria and Basidiomycota, while increasing the relative abundance of Actinbacteria, Proteobacteria and Ascomycota. Moreover, the increased proportion of bamboo litter $(0 \%$ $\mathrm{PP} \rightarrow 100 \% \mathrm{PP}$ ) increased the relative abundance of membrane transport and carbohydrate metabolism of soil bacteria but decreased the relative abundance of saprotrophic soil fungi. Redundancy analysis showed that bacteria rather than fungal communities changed greatly during incubation $(p<0.05)$. Additionally, the activities of soil $\mathrm{pH}, \mathrm{NO}_{3}{ }^{-}-\mathrm{N}, \mathrm{NH}_{4}{ }^{+}-\mathrm{N}$, dissolved nitrogen and $\mathrm{C}$ - and $\mathrm{N}$ - acquiring enzymes were the main factors affecting bacterial and fungal community structure $(p<0.05)$. The soil physicochemical properties were significantly correlated with the composition of microbial phyla among different litter amendment treatments. These results indicated that different proportions of bamboo litter dramatically alter the soil bacterial rather than the fungal community, most likely by changing edaphic patterns. This study has important implications for understanding the litter-soilmicrobe synergy during the bamboo forest expansion and provides a basis for assessing the ecological risk of bamboo forest expansion.
\end{abstract}

Keywords: soil incubation; bamboo expansion; litter composition; microbial community; functional pathway

\section{Introduction}

Litter is an important part of the forest ecosystem and is also a source of organic matter and energy for soil organisms. It has been well recognized that human disturbance and environmental changes can strongly affect forest productivity, thereby changing the input of litter on the ground [1]. Soil microorganisms play an important role in mediating the process of underground biogeochemistry [2]. In the litter-soil ecosystem, soil microorganisms can make an accurate and rapid response to small changes in the forest ecosystem [3-5]. Different litter inputs will change the soil $\mathrm{C}$ substrate matrix and then affect the soil 
microbial community. For example, changes in litter input can alter the contents of carbon $(\mathrm{C})$, nitrogen $(\mathrm{N})$, phosphorus $(\mathrm{P})$ and other nutrients, as well as the microbial community and enzyme activity [6], which will lead to changes in forest nutrient cycling. Recent studies found that enzyme activity ratios involved in $\mathrm{C} / \mathrm{N} / \mathrm{P}$ cycling are highly variable during litter decay [7]. The changes in soil enzyme activities can reflect the changes in microbial community structure. As already stated, the activities of dehydrogenase, phosphatase and urease have a close relationship with the diversity of microbial community structure [6]. Increasing evidence has indicated that microbial community structures can adapt to nutrient conditions/constraints such as $\mathrm{N}$ to control litter decomposition [8], which implies feedback between decomposition and microbial composition when aboveground vegetation changes. Some studies have found that mixed litter may provide more diverse ecological niches for decomposing microorganisms [9-11], thus affecting microbial community structure and function. Therefore, compared with litter decomposition of a single plant species, mixedlitter decomposition can improve soil microbial community richness and diversity [12,13]. So far, there have been few studies on the variation dynamics of soil microbial community structure caused by mixed-litter decomposition, and the interactions between them are still unclear.

Furthermore, bacteria and fungi in soil vary widely in terms of growth strategy competitiveness and how they use resources. In general, bacterial decomposition pathways mainly regulate easily decomposed substrates with high turnover, while fungal communities mainly regulate more complex organic materials with slower turnover [14]. The richness and relative abundance of fungi and bacteria are important characteristics of soil microbial communities, and some studies have shown that the change in litter quality will change soil microbial composition [3,15-18]. Therefore, plant expansion or invasion will undoubtedly change the structure and activities of soil microbial communities through litter (such as stoichiometry [19]). However, the contribution of bacteria and fungi to specific processes in the ecosystem is different. For example, fungi are thought to decompose mainly complex and stubborn plant litters, particularly lignin and cellulose. In contrast, the contribution of bacteria to the decomposition of lignin and humus is not significant. This is because fungi have lower nutritional requirements than bacteria, show higher carbon utilization efficiency on low-quality substrates and have the ability to degrade complex substrates [20]. Bacteria generally have rapid growth and regeneration rates, contain higher amounts of nitrogen, phosphorus and organic compounds and are favorable for survival at lower substrate $\mathrm{C} / \mathrm{N}$ ratios. In addition, litter diversity will also affect the composition and structure of the microbial community. Litter in a mixture than in a monoculture could decrease Acidobacteria and Solibacteres but increase Dothideomycetes [3]. However, the response of soil microorganisms to litter input remains controversial $[15,18]$. How forest types with different soil conditions (e.g., whether the forest is disturbed by plant expansion) interact with microbial composition and dynamics during litter decomposition remains elusive.

The rapid expansion of bamboo has been widely reported in many countries due to its fast growth and large-scale clonal reproduction, leading to actual and potential changes in the structure and function of the ecosystem [8]. For example, the expansion of bamboo forest into the surrounding forest ecosystem may lead to increased decomposition of litter and nutrient turnover. The higher the proportion of bamboo in mixed litters, the faster the decomposition rate and nutrient regression of litters [21]. Compared with broadleaf litter, bamboo litter generally has a lower carbon to nitrogen ratio and lignin concentration, as well as lower folic acid alkalinity in litters. In this study, the effects of bamboo litter on the composition and function of soil microbial community in broadleaf forest soil during the expansion process were studied by adding different proportions of bamboo and broadleaf litters in laboratory incubation experiments. Broadleaf litter was used as a positive control, and no litter was used as a negative control. Since soil microorganisms play an important role in ecosystem functions, the study of the microbial community in the bamboo-broadleaved forest ecosystem will provide a theoretical basis for understanding 
the nutrient cycling function of bamboo forest during its expansion into the broadleaved forest ecosystem.

\section{Materials and Methods}

\subsection{Soil and Litter Sampling}

The experimental soils were collected from a broadleaved forest, located at the Lingfeng Mountain Reserve, An'ji County, Zhejiang province, China $\left(30^{\circ} 36^{\prime} \mathrm{N}, 119^{\circ} 63^{\prime} \mathrm{E}\right)$. The site has a monsoon subtropical climate with a mean air temperature of $16.1{ }^{\circ} \mathrm{C}$ and an average annual precipitation of $1431 \mathrm{~mm}$ [22]. The soil is classified as a Ferrasols in the Food and Agriculture Organization of the United Nations (FAO) soil classification system. The region is rich in vegetation resources with woody plants from 64 families and 231 species. Common conifer species are Pinus massoniana and some artificial wetland pine forest. The deciduous broadleaved trees are Quercus acutissima Carruth and Quercuschenii Nakai. Evergreen broadleaved trees include Cyclobalanopsis glauca, Castanopis sclerophylla and Schimasuperba Gardn. All of the trees are over 50 years old, with a high stand density of undergrowth shrubs and weeds.

In October 2018, five replicate soil blocks $\left(25 \mathrm{~m}^{2} \times 20 \mathrm{~cm}\right.$ depth) were collected randomly from the broadleaved forest and pooled to form a composite soil sample. All the dead or live roots and plant debris were removed from the soil. The soil sample was then passed through a $2 \mathrm{~mm}$ sieve, and the resultant sample was mixed thoroughly to form a homogenized bulk sample. The soil had a $\mathrm{pH}\left(\mathrm{H}_{2} \mathrm{O}\right)$ of 4.20, soil organic carbon (SOC) concentration of $33.45 \mathrm{~g} \mathrm{~kg}^{-1}$ and total $\mathrm{N}$ (TN) concentration of $1.35 \mathrm{~g} \mathrm{~kg}^{-1}$. Plant litter was collected from nylon mesh bags randomly distributed in the pure broadleaved and bamboo forest and their mixed forest. Including bamboo leaves, a mixture of broadleaved leaves, Cyclobalanopsis glauca, Castanopsis sclerophylla and Quercus acutissima Carruth, were collected. Litters were washed carefully with ultrapure water to remove impurities and then dried at $60^{\circ} \mathrm{C}$ for $12 \mathrm{~h}$. One part of the dried litters was ground $(<0.5 \mathrm{~mm})$ to measure its characteristics, such as $\mathrm{C}$ and $\mathrm{N}$ contents. The litters of bamboo, Cyclobalanopsis glauca, Castanopsis sclerophylla and Quercus acutissima Carruth had a C content of 359.1, 427.8, 436.3 and $463.6 \mathrm{mg} \mathrm{C} \mathrm{g}^{-1}$ dry mass and a $\mathrm{N}$ content of $11.5,14.4,9.9$ and $13.5 \mathrm{mg} \mathrm{N} \mathrm{g}^{-1}$ dry mass. The litter properties among different treatments are shown in Table 1. 
Table 1. Litter $\mathrm{C}, \mathrm{N}$ and $\mathrm{C} / \mathrm{N}$ ratio of different leaf litter treatments.

\begin{tabular}{|c|c|c|c|c|c|c|c|}
\hline Treatment & Litter Composition & $\begin{array}{c}\text { Quantity of Litter/g } \\
100 \mathrm{~g}^{-1} \text { soil }\end{array}$ & Total C/mg g ${ }^{-1}$ & Total N/mg g $\mathbf{~}^{-1}$ & $\mathrm{C} / \mathrm{N}$ & Lignin/\% & Cellulose/\% \\
\hline $0 \% \mathrm{PP}$ & Broadleaved & 1 & $442.58 \pm 10.78 \mathrm{~d}$ & $12.57 \pm 1.38 \mathrm{a}$ & $36.23 \pm 4.27 a$ & $49.15 \pm 1.15 \mathrm{~b}$ & $11.83 \pm 0.53 \mathrm{a}$ \\
\hline $33 \% \mathrm{PP}$ & Broadleaved + Bamboo & $0.667+0.333$ & $414.76 \pm 12.13 c$ & $12.21 \pm 0.96 \mathrm{a}$ & $34.61 \pm 2.80 \mathrm{a}$ & $48.48 \pm 1.15 \mathrm{ab}$ & $11.58 \pm 0.49 \mathrm{a}$ \\
\hline $50 \% \mathrm{PP}$ & Broadleaved + Bamboo & $0.5+0.5$ & $400.84 \pm 5.12 \mathrm{bc}$ & $12.04 \pm 0.78 \mathrm{a}$ & $33.79 \pm 2.16 a$ & $48.15 \pm 1.15 \mathrm{ab}$ & $11.46 \pm 0.48 \mathrm{a}$ \\
\hline $67 \% \mathrm{PP}$ & Broadleaved + Bamboo & $0.333+0.667$ & $386.93 \pm 3.23 b$ & $11.86 \pm 0.64 \mathrm{a}$ & $32.98 \pm 1.64 \mathrm{a}$ & $47.82 \pm 1.15 \mathrm{ab}$ & $11.33 \pm 0.46 a$ \\
\hline $100 \%$ PP & Bamboo & 1 & $359.10 \pm 0.55 \mathrm{a}$ & $11.50 \pm 0.59 a$ & $31.35 \pm 1.60 \mathrm{a}$ & $45.15 \pm 0.29 \mathrm{a}$ & $10.45 \pm 0.20 \mathrm{a}$ \\
\hline
\end{tabular}
occupying at $100 \%$; the same below. Data are means \pm S.D., $n=3$. Different letters in a single row indicate significantly different means according to Duncan's test at $p<0.05$ level. 


\subsection{Experimental Design}

To eliminate spatial variation in microclimate, soil heterogeneity and the rhizospheric effect, we used a microcosm approach to investigate the short-term effects of change in litter quality induced by bamboo invasion into the broadleaved forest on soil microbiome. We prepared a series of mixed-species litters with bamboo litter occupying at the $0 \%, 33 \%, 50 \%$, $67 \%$ and $100 \%$ proportion (with a decrease in litter $\mathrm{C} / \mathrm{N}$ from 36.23 to 31.35 ) to generally simulate the proportional changes in leaf litter composition under bamboo invasion. Six treatments, including a non-amended negative control (CK), $\%$ PP (broadleaved leaf litter only), 33\% PP (broadleaved leaf litter/bamboo leaf litter $=2: 1$ ), 50\% PP (broadleaved leaf litter $/$ bamboo leaf litter = 1:1), 67\% PP (broadleaved leaf litter/bamboo leaf litter $=1: 2$ ) and $100 \%$ PP (bamboo leaf litter only) were set in this experiment. Respective oven-dried litter ( $1 \mathrm{~g}$ dry mass) was amended into $100 \mathrm{~g}$ of dry soil (at a rate of $1 \%$ according to the annual litter input of the bamboo forest) [23], and then treated soils were incubated in sterilized sealed glass jars (1 L) at $25{ }^{\circ} \mathrm{C}$ in the dark for 6 months. Soil moisture was adjusted to $60 \%$ of water-holding capacity with deionized water and was maintained throughout the incubation period by weighing the jars twice a week and adding deionized water when necessary. In total, there were 15 replicates per treatment constructed in this study, which permitted the destructive sampling of three replicates for each treatment at Days 5, 15, 30, 90 and 180 for microbiome analyses. One subsample from each sample (15 g) was frozen and stored at $-80^{\circ} \mathrm{C}$ for later DNA extraction and amplicon sequencing. Another subsample around $50 \mathrm{~g}$ of soil was stored at $4{ }^{\circ} \mathrm{C}$ for no longer than 1 week prior to soil enzyme activity, soil microbial biomass, soil nitrate $\left(\mathrm{NO}_{3}{ }^{-}-\mathrm{N}\right)$ and soil ammonium $\left(\mathrm{NH}_{4}{ }^{+}-\mathrm{N}\right)$ analyses. The bulk of the remaining soil was air-dried at room temperature for characterization of physicochemical properties.

\subsection{Analyses of Soil Properties and Soil Enzyme Activities}

Soil $\mathrm{pH}$ was measured in a 1:2.5 soil-to-water ratio using a $\mathrm{pH}$ meter (Mettler-Toledo, Switzerland). SOC and TN were determined by wet digestion using $\mathrm{K}_{2} \mathrm{CrO}_{7}$ oxidation and the Kjeldahl method, respectively, according to $\mathrm{Lu}$ [24]. Dissolved organic carbon (DOC) and dissolved $\mathrm{N}(\mathrm{DN})$ were extracted by the method of Justine [25], in which the DOC was extracted by the TOC-L CPH CN200 (Tokyo, Japan), and DN in the extracts was determined by the semi-micro-Kjeldahl method. Soil nitrate $\left(\mathrm{NO}_{3}{ }^{-} \mathrm{-N}\right)$ and ammonium $\left(\mathrm{NH}_{4}{ }^{+}-\mathrm{N}\right)$ contents were extracted by $50 \mathrm{~mL}$ of $0.5 \mathrm{M} \mathrm{KCl}$ and then determined by the Skalar SAN++ (WestCo Scientific Instruments, Brookfield, CT, USA) [26]. Net N mineralization for each treatment from each stage was quantified by subtracting the $\mathrm{N}$ content of extractable minerals found in each treatment from the $\mathrm{N}$ content of extractable minerals found in the unmodified control soil [27].

Activities of four C-acquiring enzymes, including $\alpha$-1,4-glucosidase (AG), $\beta-1,4$ glucosidase (BG), $\beta$-D-cellobiosidase (CB), and $\beta$-1,4-xylosidase (XYL); two $N$-acquiring enzymes, including $N$-acetyl- $\beta$-D-glucosaminidase (NAG) and leucine aminopeptidase (LAP); and one P-acquiring enzyme (acid phosphomonoesterase (AP)) were assayed according to the methods described previously by Chen [28].

\subsection{DNA Extraction and Amplicon Sequencing}

DNA was extracted from $0.25 \mathrm{~g}$ of frozen soil using the PowerLyzerPowerSoil Kit (QIAGEN) according to the manufacturer's protocol. The extracted DNA concentration and purity were determined with the NanoDrop2000 spectrophotometer (Thermo Fisher Scientific, Waltham, MA, USA). DNA integrity was examined on $1 \%$ agarose gels and then stored at $-40{ }^{\circ} \mathrm{C}$ until use.

Bacterial and fungal communities were assessed through variation in their $16 \mathrm{~S}$ and ITS rRNA gene sequence, in which the specific primer pairs were 338F/806R and ITS3F/ITS4R, respectively. Paired-end sequencing was performed on an Illumina HiSeq 400 platform (Illumina, San Diego, CA, USA) at Shanghai Majorbio Bio-Pharm Technology Co., Ltd. These sequences were assigned to the sample using a specific barcode and stored in a 
FASTQ-formatted file. Raw data FASTQ files were analyzed using the software pipeline Vsearch version 2.8.1 [29].

Raw overlapping $16 \mathrm{~S}$ paired-end reads were merged, and merged sequences with an overlap length smaller than $200 \mathrm{bp}$ and with more than 50 mismatches were discarded. After primer and barcode trimming, merged reads with an expected error rate higher than $1 \%$ were removed. Sequences with the smallest single base number less than 10 were discarded. Filtered sequences were clustered into operational taxonomic units (OTUs) at 97\% identity and RDP-based chimera detected using Usearch version 11.0 (http:/ / www. drive5.com/usearch/ accessed on 1 December 2021). OTUs were taxonomically classified using the RDP database. With 0.6 as the confidence threshold, the OTU representative sequence was compared with the RDP database to obtain the taxonomic information of the representative OTU sequence. The representative sequences of each OTU were annotated to obtain the corresponding species information and relative abundance distribution. PICRUSt was used to standardize the OTU abundance table and obtain the corresponding KEGG Orthology $(\mathrm{KO})$ information. KEGG Pathway information was obtained based on KEGG database information, and the abundance of each functional category was calculated based on OTU abundance.

Raw overlapping ITS paired-end reads were merged, and merged sequences with an overlap length smaller than $100 \mathrm{bp}$ and with more than 30 mismatches were discarded. After primer and barcode trimming, merged reads with an expected error rate higher than $1 \%$ were removed. Sequences with the smallest single base number less than 10 were discarded. Filtered sequences were clustered into operational taxonomic units (OTUs) at $97 \%$ identity, and with 0.6 as the confidence threshold, the OTU representative sequences were taxonomically classified with the UNITE database [30]. Sequences that were not in the UNITE database were indicated as "Unassigned", while sequences that were present in the UNITE database but without taxonomic information available were classified as "unclassified_k_Fungi" for the taxonomic level. The FUNGuild microecological tool was used to predict and analyze the function of soil fungi according to the nutrient pattern.

\subsection{Statistical Analyses}

Simple files were imported into R v.3.5.0 [31] and Rstudio for downstream statistical analysis. To compensate for the different sequencing depths, the samples were sparser at 9000 depths in $16 \mathrm{~S}$ and 32,000 depths in ITS sequences. Alpha-diversity was calculated using the Chao1, Shannon and OTU number index. Beta-diversity was calculated using the Bray-Curtis (BC) distance. Based on the BC dissimilarity index, redundancy analysis (RDA) and analysis of similarity (ANOSIM) with 999 permutations were conducted in the "vegan" package. The significance of environmental variables was fitted with "envfit", via which the correlation test of the combination of microbial matrix and environment variables was carried out. Repeated measurement analysis of variance (RMANOVA) was performed to identify the temporal effects of leaf litter addition on microbial alpha-diversity. A value of $p<0.05$ was considered to be statistically significant.

\section{Results}

\subsection{Bacterial Community Composition and Functional Pathways}

As shown in Supplementary Materials Figure S1A, Actinobacteria (32.1\%) and Proteobacteria $(29.1 \%)$ were dominant in all six treatments. Compared with the $0 \%$ PP treatment, the relative abundance of Actinobacteria and Proteobacteria increased, while the relative abundance of Acidobacteria decreased (except on the 30th day of incubation) with the increasing proportion of bamboo litter. At the class level (Figure 1A), Actinobacteria (21.27-42.51\%), Alphaproteobacteria (16.56-25.81\%) and Acidobacteria (6.81-17.35\%) were the dominant bacterial classes in all six treatments. With the increase in incubation time, the relative abundance of Saccharimonadia, Bacteroidia and Deltaproteobacteria in each treatment increased at the early stage and then decreased after 30 days of incubation. The relative abundance of Actinobacteria showed opposite variation in the $100 \%$ PP and 0\% PP treatments that de- 
creased in $0 \%$ PP (from $35.92 \%$ to $32.01 \%$ ) but increased in 100\% PP (from $37.13 \%$ to $38.15 \%$ ) during incubation.
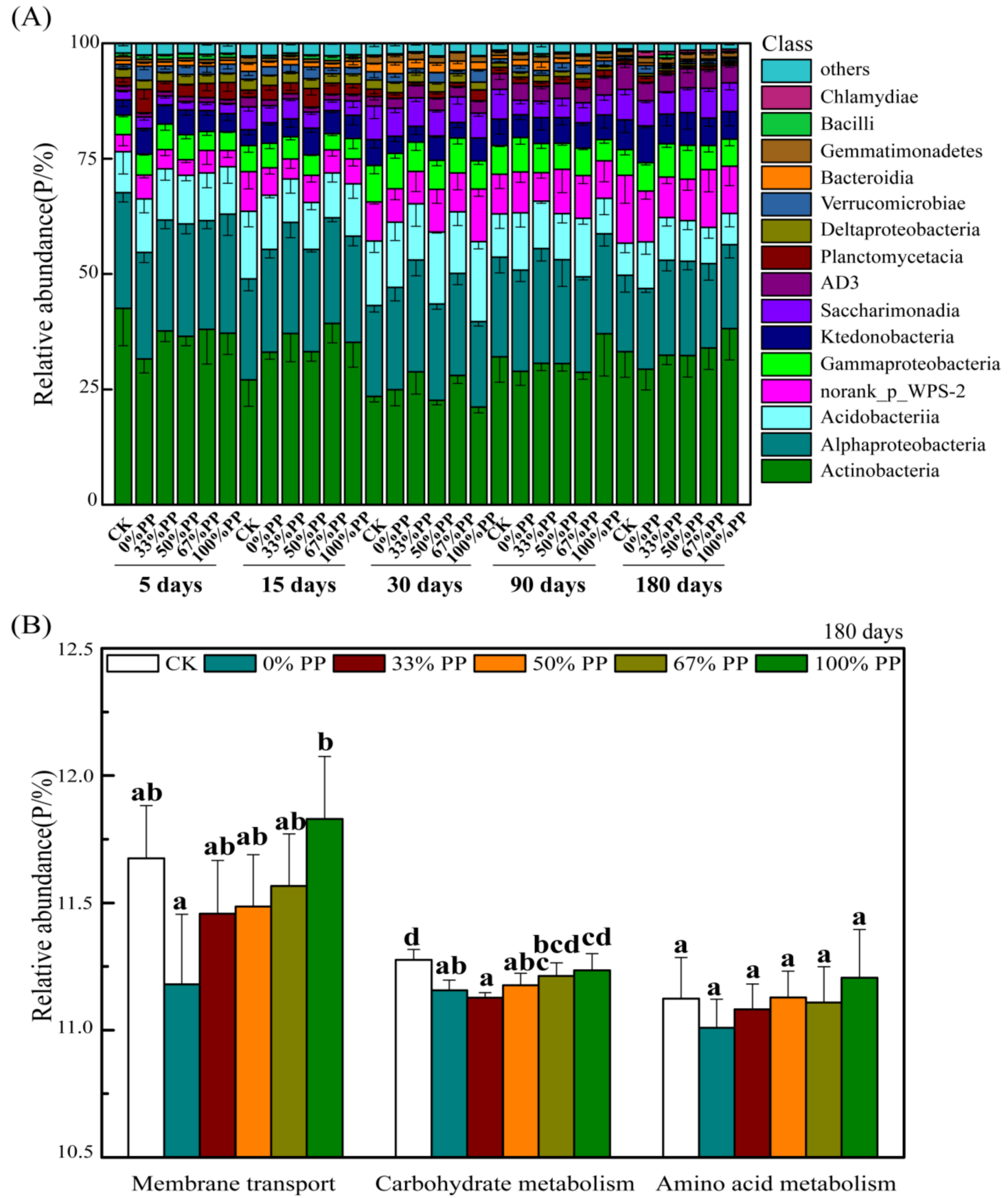

Figure 1. The community composition (A) and functional pathways (B) of bacteria at the level of class in the broadleaved forest soil during incubation. $\mathrm{CK}$, with no litter; $0 \% \mathrm{PP}$, bamboo litter occupying at $0 \% ; 33 \%$ PP, bamboo litter occupying at 33\%; 50\% PP, bamboo litter occupying at 50\%; $67 \%$ PP, bamboo litter occupying at $67 \% ; 100 \% \mathrm{PP}$, bamboo litter occupying at $100 \%$. Bars with different letters among different treatments are significantly different $(p<0.05)$.

Based on the KEGG function classification, we obtained seven bacteria metabolic functional pathways, which have a total of 41 subfunctions. At the end of incubation (180 days), the most abundant functional pathways were carbohydrate metabolism and amino acid metabolism, followed by genetic information processing and environmental information processing (membrane transport) (Figure 1B). The results showed that different 
bamboo litter proportions had significant effects on membrane transport and carbohydrate metabolism $(p<0.05)$. Moreover, the relative abundance of the functional pathways of membrane transport, carbohydrate metabolism and amino acid metabolism in 100\% PP treatment was higher than that in other treatments (Figure 1B).

\subsection{Fungal Community Composition and Functional Pathways}

As shown in Supplementary Materials Figure S1B, Ascomycota (53.88-84.17\%), Basidiomycota (8.88-27.25\%) and Mucoromycota (4.07-10.72\%) were the dominant fungi during litter decomposition in the six treatments. Thirty days after incubation, the relative abundance of Ascomycota was significantly increased, and that of Basidiomycota was significantly decreased with the addition of bamboo litter compared with the $0 \%$ PP treatment. At the class level (Figure 2A), Sordariomycetes (9.49-38.41\%), unclassified_p_Ascomycota (8.61-39.64\%) and Eurotiomycetes (9.44-25.80\%) dominated the fungal community. The addition of litters significantly increased the relative abundance of Sordariomycetes and Dothideomycetes and decreased that of Eurotiomycetes. In particular, the relative abundance of Dothideomycetes decreased (from $13.54 \%$ to $5.5 \%$ ) in the $67 \%$ and $100 \%$ PP treatments but increased (from $6.45 \%$ to $11.14 \%$ ) in $0 \%$ and $33 \%$ PP treatments.

Based on the FUNGuild function classification, we obtained three functional groups based on how they acquire their energy. At the end of incubation (180 days), the most abundant functional pathway was saprotroph (fungal parasite-undefined saprotroph and endophyte-litter saprotroph-Soil saprotroph-Undefined saprotroph), followed by symbiotroph (ectomycorrhizal) (Figure 2B). Bamboo litter proportion had no effect on fungal functional pathways ( $p>0.05)$, except for fungal parasite-undefined saprotroph. However, bamboo litter decreased the relative abundance of these three functional pathways (Figure 2B)

\subsection{Bacterial and Fungal $\alpha$-Diversity Vary with Litter Type and Incubation Time}

The microbiome richness, or $\alpha$-diversity, varied greatly across different litter ratios and incubation times for both bacteria and fungi (Figure 3). The Chao1, OTU number and Shannon index of the bacteria community increased with litter addition, while richness and evenness gradually decreased during incubation (Figure $3 \mathrm{~A}-\mathrm{C}$ ). Compared with the $0 \% \mathrm{PP}$ treatment, the increased proportion of bamboo litter $(33 \% \mathrm{PP} \rightarrow 100 \% \mathrm{PP})$ decreased the Chao1, OTU number and Shannon index of the bacterial community during incubation. For the fungal community, litter type had a non-significant effect on fungal $\alpha$-diversity (Figure 3D-F), but incubation time significantly affected fungal $\alpha$-diversity. The addition of litter increased the Chao1 index and OTU number compared with CK before 90 days of incubation.

\subsection{Contributions of Environmental Factors to Microbial Community Structure}

Redundancy analysis showed that there were significant differences in soil bacterial community structure at different incubation stages (Figure 4A), which were greatly affected by soil chemical properties (Supplementary Materials Table S1). The main variables significantly affecting bacterial community structure were soil $\mathrm{pH}, \mathrm{NO}_{3}{ }^{-}-\mathrm{N}$ and $\mathrm{DN}(p<0.001)$. In particular, the soil bacterial communities of the different litter treatments were negatively correlated with $\mathrm{NO}_{3}{ }^{-}-\mathrm{N}, \mathrm{DN}$ and LAP activities but positively correlated with $\mathrm{pH}, \mathrm{C}$ and N-acquiring enzyme activities (Supplementary Materials Figure S2) at the early stage of incubation. 

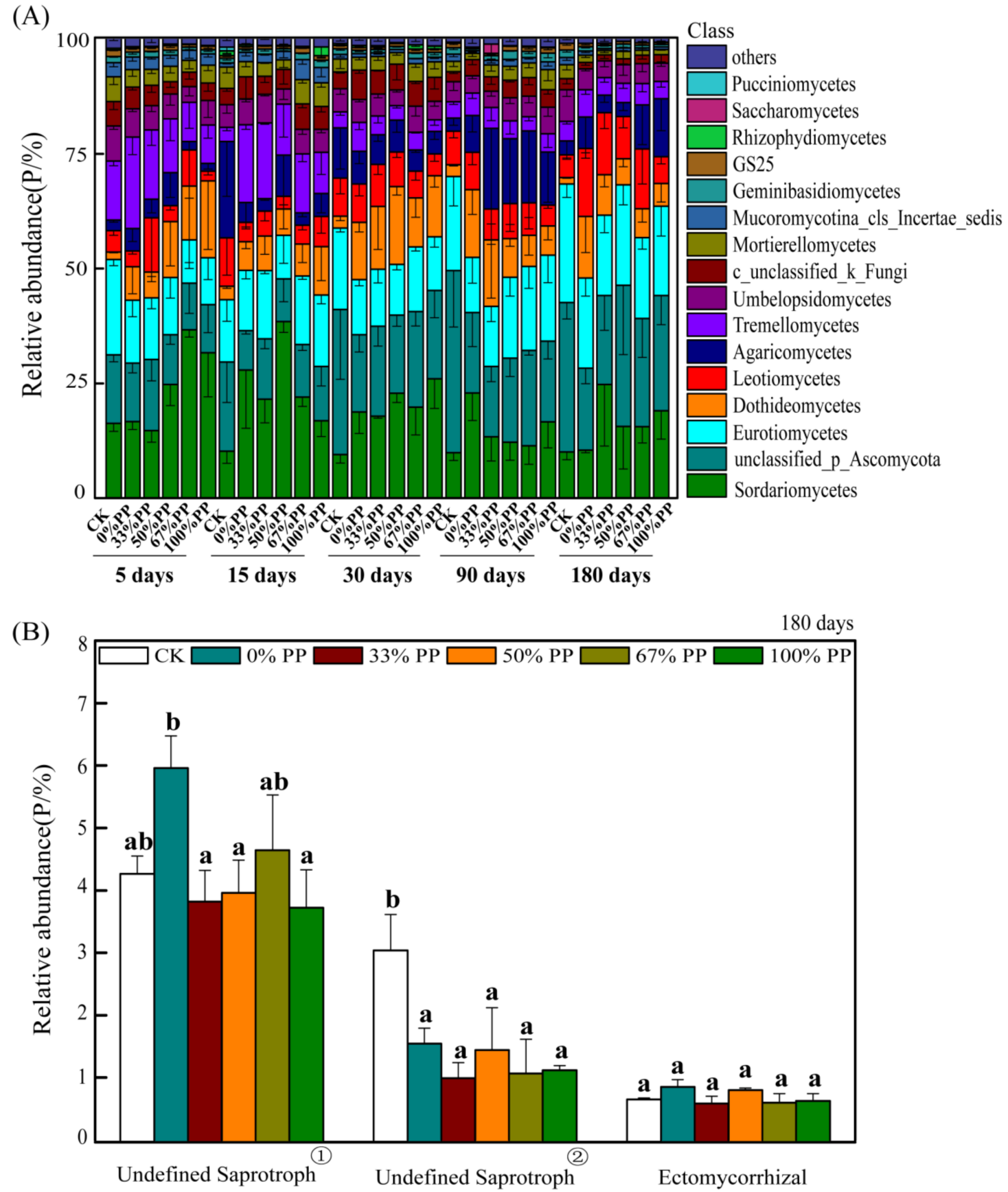

Figure 2. The community composition (A) and functional pathways (B) of the fungal community at the level of class in the broadleaved forest soil during incubation. Undefined Saprotroph (1)): Fungal Parasite-Undefined Saprotroph; Undefined Saprotroph (2): Endophyte-Litter Saprotroph-Soil Saprotroph-Undefined Saprotroph. CK, with no litter; $\% \%$ PP, bamboo litter occupying at $0 \%$; 33\% $\mathrm{PP}$, bamboo litter occupying at 33\%; 50\% PP, bamboo litter occupying at 50\%; 67\% PP, bamboo litter occupying at $67 \% ; 100 \%$ PP, bamboo litter occupying at $100 \%$. Error bars indicate standard deviation. Different letters show significant differences $(p<0.05)$. 

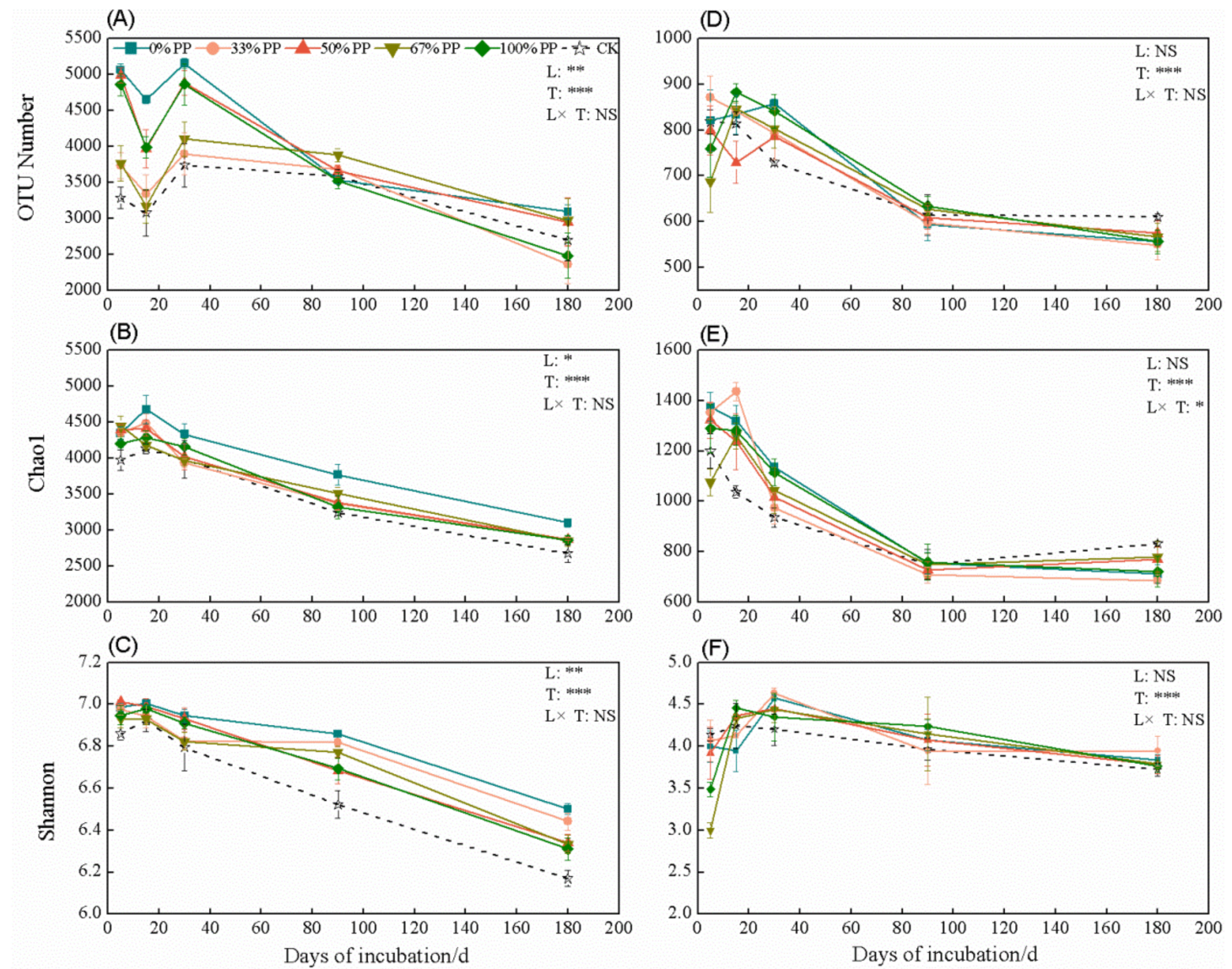

Figure 3. Effects of litter type (0 \% PP, 33\% PP, 50\% PP, 67\% PP, 100\% PP) on bacterial (A-C) and fungal (D-F) alpha-diversity. Error bars indicate standard deviation. $p$-values from RMANOVA on the effects of the litter type (L) and incubation time $(\mathrm{T})$ are also presented. CK, with no litter; $0 \%$ PP, bamboo litter occupying at 0\%; 33\% PP, bamboo litter occupying at 33\%; 50\% PP, bamboo litter occupying at 50\%; 67\% PP, bamboo litter occupying at $67 \% ; 100 \%$ PP, bamboo litter occupying at $100 \%$. Error bars indicate standard deviation.
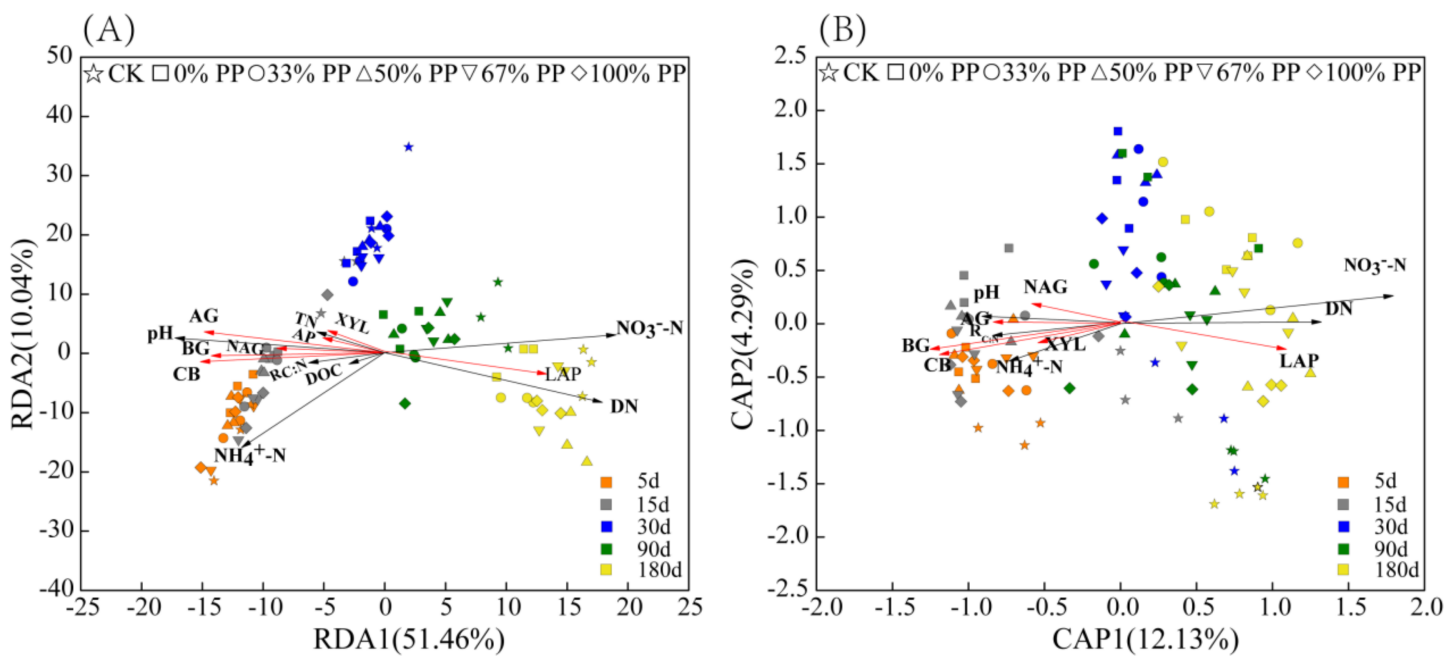

Figure 4. The redundancy analysis (RDA) ordination plots of the community compositions of bacteria (A) and fungal (B) communities. CK, with no litter; $0 \% \mathrm{PP}$, bamboo litter occupying at $0 \%$; 33\% PP, bamboo litter occupying at 33\%; 50\% PP, bamboo litter occupying at 50\%; 67\% PP, bamboo litter occupying at $67 \% ; 100 \%$ PP, bamboo litter occupying at $100 \%$. 
Neither litter treatments nor incubation stages had a significant effect on soil fungal community structure (Figure 4B). The main variables significantly affecting fungal community structure were soil $\mathrm{pH}, \mathrm{NO}_{3}{ }^{-}-\mathrm{N}, \mathrm{NH}_{4}{ }^{+}-\mathrm{N}, \mathrm{DN}$ and $\mathrm{C}$ - and $\mathrm{N}$-acquiring enzyme activities $(p<0.001)$.

\subsection{Impact of Environmental Factors on Bacterial and Fungal Taxa}

The correlation heat map results showed that Chloroflexi, Patescibacteria and Planctomycetes were the three most significant bacterial groups affected by environmental factors (Figure 5A). Notably, Acidobacteria, Planctomycetes and Proteobacteria were positively related to $\mathrm{pH}$ and C-acquiring enzyme activities, while Chloroflexi, Patescibacteria and WPS-2 were negatively related to $\mathrm{pH}, \mathrm{NH}_{4}{ }^{+}-\mathrm{N}$ and $\mathrm{C}$-acquiring enzyme activities $(p<0.001)$. The main variables significantly affecting bacterial community composition were $\mathrm{pH}$, mineral- $\mathrm{N}\left(\mathrm{NO}_{3}{ }^{-}-\mathrm{N}\right.$ and $\left.\mathrm{NH}_{4}{ }^{+}-\mathrm{N}\right), \mathrm{DN}$ and C-acquiring enzyme activities.

(A)

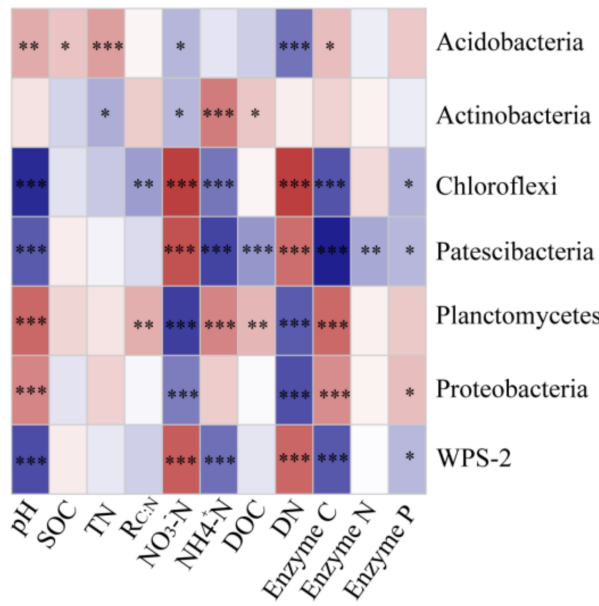

(B)

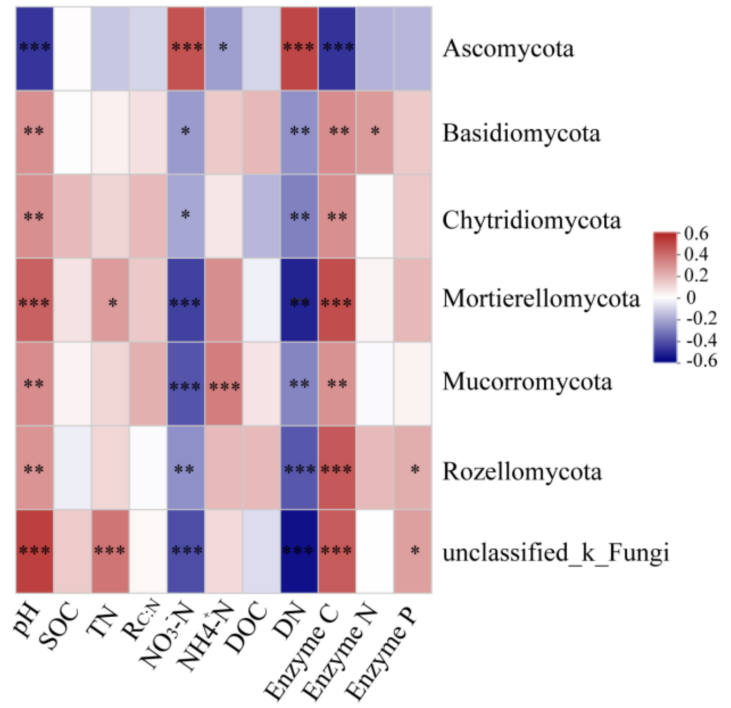

Figure 5. The heat map of the relationship between species and environmental factors at the phylum level of bacteria (A) and fungal (B) communities. Significance level: ${ }^{*}, p<0.05 ;{ }^{* *}, p<0.01$; $* * *, p<0.001$.

However, fungal community composition at the phylum level was not significantly affected by SOC and $\mathrm{R}_{\mathrm{C}: \mathrm{N}}$ (the ratio of SOC to TN) (Figure 5B). Besides Ascomycota, all fungal phyla were positively correlated to $\mathrm{pH}$ and $\mathrm{C}$-acquiring enzyme activities but negatively correlated to $\mathrm{NO}_{3}{ }^{-}-\mathrm{N}$ and DN. The main variables significantly affecting fungal community composition were $\mathrm{pH}, \mathrm{NO}_{3}{ }^{-}-\mathrm{N}, \mathrm{DN}$ and $\mathrm{C}$-acquiring enzyme activities.

\section{Discussion}

\subsection{Effects of Litter on Soil Bacterial and Fungal Community Structure}

Litter is an important source of soil organic matter, and changes in the input of litter can affect the soil microbial community structure by changing soil available nutrient content [32]. The addition of different types of litter and their decomposition process will change the quality of litter and the content and availability of nutrients to the native microorganisms in the soil. Thus, the soil microbial community will make corresponding adjustments to respond to these changes. In this study, the OTU number of bacteria in the soil changed significantly after the addition of different proportions of bamboo litter. Moreover, with the increase in bamboo litter proportion, the OTU number of soil bacteria increased significantly. This may be due to the faster decomposition rate of bamboo litter and the faster return of nutrients in litter. Soil bacteria have more nutrient sources, allowing them to proliferate. The results of this study also showed that the richness index and 
uniformity index of the soil bacterial and fungal communities increased significantly in litter addition compared with CK (Figure 3). Different proportions of bamboo litter changed the bacterial diversity but had no effect on the fungal diversity. With the increase in the proportion of bamboo litter, the Chao1 index, OTU number and Shannon index of the bacterial community decreased. However, this study found that litter quality had no significant effect on the $\alpha$-diversity of soil fungal communities $(p>0.05)$. These results support the findings of Wang et al. [33] and Xing et al. [34], which reported the fungal community composition converged from the early to the late stage. However, this is inconsistent with previous studies reported in changes in litter quality induced by $\mathrm{N}$ deposition [18], in which changes in litter quality increased the diversity of the fungal community, and higher fungal diversity was observed in soil with mixed litter.

The structure of the soil bacteria community is more sensitive to the change in soil chemical properties than the fungal community. However, the addition of different litter types does not have a unified conclusion on the changes in soil bacteria community structure $[15,16,18,33,35]$. In this study, we found that there were significant differences in the community structure of bacteria rather than fungi at different incubation stages (Figure 4). Moreover, soil bacteria communities were significantly different between the $0 \%$ PP and $100 \%$ PP treatments at the end of incubation, suggesting that differences in litter species constructed different soil bacterial communities. The main reason for the above differences may be that the input of aboveground litter of different tree species changed the effective nutrient content, leading to the change in available carbon source for microorganisms [15]. Redundancy analysis (RDA) showed that soil bacterial community structure was significantly correlated with $\mathrm{pH}, \mathrm{DOC}, \mathrm{NH}_{4}{ }^{+}-\mathrm{N}$ and $\mathrm{C}$ - and $\mathrm{N}$-acquiring enzyme activities at the early stage of incubation (30 d) but significantly correlated with $\mathrm{NO}_{3}{ }^{-}-\mathrm{N}$ and $\mathrm{DN}$ at the late stage ( $90 \mathrm{~d}$ ) (Figure 3A). It showed that the microorganisms were mainly limited by $\mathrm{N}$ source in the early stage of culture, while the $\mathrm{N}$ limit gradually decreased with the increase in the proportion of bamboo litter. At the later stage of incubation, as the proportion of bamboo litter increases, the imbalance of $\mathrm{C}$ and $\mathrm{N}$ may promote the metabolic control of the soil-litter system and play a key role in shifting from $\mathrm{N}$ restriction to $\mathrm{C}$ restriction [36]. In this study, pure broadleaved forest soil was used to investigate the effects of litter type and bamboo litter proportion on the native soil microbial communities during the invasion of bamboo forest. There was no significant difference in fungal community structure, which may be due to the fact that fungi mainly decompose complex and stubborn plant litter $[14,20]$. However, since the incubation time of this experiment was only 180 days, the decomposition of litters was still dominated by easily decomposed substances during the incubation period, resulting in no significant difference in the structure of the fungal community from litter treatment.

\subsection{Effect of Bamboo Litter on Bacterial and Fungal Community Composition and Function Pathways}

Changes in microbial communities mediated by leaf litter quality also affect soil ecosystem functions $[34,37,38]$. Many studies have found that Proteobacteria, Actinobacteria and Ascomycota are the most abundant phyla in the early stage of litter decomposition and are considered to be the main decomposers [3]. In this study, we found that in the five decomposition stages, Actinobacteria and Proteobacteria are dominant in the bacterial community, and Ascomycota is dominant in the fungal community (Figures 1 and 2). With the increasing proportion of bamboo litter, the relative abundance of Actinobacteria and Proteobacteria was higher than $0 \%$ PP, while the relative abundance of Acidobacteria was lower than $0 \%$ PP. Acidobacteria are typical oligotrophic bacteria, while Proteobacteria are eutrophic bacteria, which are suitable for soil environments with high nutrient content. This indicates that the decomposition rate of litter with the higher proportion of bamboo litter results in the rapid return of litter nutrients and the improvement of soil nutrient availability. This leads to an increase in the relative abundance of Proteobacteria and Actinbacteria and a decrease in the relative abundance of Acidobacteria. Previous studies showed that Acidobacteria 
plays an important role in lignin degradation, and bamboo litter usually contains less than broadleaf litter. This study also found that compared with $0 \% \mathrm{PP}$, the relative abundance of Ascomycota was significantly increased, while Basidiomycota was significantly decreased with the increasing proportion of bamboo litter in the first 30 days of incubation (Figure 2). We can hypothesize that the decomposition of litter will reduce the number of readily available compounds, leaving more difficult-to-use compounds. Nevertheless, Basidiomycota may be easier to use refractory compounds than Ascomycota. The quality of plant litter is considered to be the dominant factor affecting nutrient release [39]. The ratio of carbon to nitrogen is usually an important attribute of litter quality, which has a certain impact on the composition of soil microbial communities [18,33]. In addition, through correlation analysis, we found that soil $\mathrm{pH}, \mathrm{NO}_{3}{ }^{-} \mathrm{N}, \mathrm{DN}$ and $\mathrm{C}$-acquisition enzyme activity have a significant impact on the composition of the soil bacteria and fungi community $(p<0.05)$. It is well known that soil $\mathrm{pH}$ has a significant effect on microbial community composition and functional pathways [3]. In this study, soil $\mathrm{pH}$ was positively correlated with the three dominant bacterial taxa (Actinobacteria, Proteobacteria and Acidobacteria) and Basidiomycota while negatively correlated with Ascomycota (Figure 5). This indicated that the different availability of nutrients released into soil during litter decomposition can affect soil $\mathrm{pH}$ and result in the variation of dominant soil microbial species.

The effect of vegetation on soil microbial community structure will further affect the functional pathway of soil bacteria and fungi. In this study, soil bacteria mainly involved 7 primary functional layers and 41 secondary functional layers. Among them, the metabolic function of soil bacteria is active and extremely important. For example, the membrane transport function is conducive to maintaining various life activities of the bacteria, which is the basis for the normal function of soil bacteria [40]. Carbohydrate metabolism is closely related to the effects of nitrogen fixation and phosphorus solubilization, which is beneficial to the nitrogen and phosphorus cycles of plants [41]. Amino acid metabolism can help bacteria absorb amino acids, which is conducive to the survival and reproduction of bacteria [42]. In this study, we found that the addition of bamboo litter increased the relative abundance of amino acid and carbohydrate metabolism genes. This further reflects an important adaptive strategy of bacteria to cope with the shortage of resources; namely, bamboo litter makes the microorganisms switch from $\mathrm{N}$ to $\mathrm{C}$ limitation. FUNGuild was used to predict the ecological functions of soil fungi in this study. From the perspective of nutrition type, the saprophytic type was the most important nutrition type, which may be related to Ascomycota, the most dominant phylum. Ascomycota, mostly saprophytes, is an important decomposer in soil, which can decompose difficult-to-degrade organic matter and plays an important role in nutrient cycling.

\section{Conclusions}

Our study provides direct evidence of the impact of bamboo expansion on the soil microbial community in broadleaved forest soil by adding different proportions of bamboo litter. We found changes in soil microbial community structure and function pathway caused by mixing bamboo with broadleaved litter in different proportions, which was attributed to the increase in soil $\mathrm{N}$ availability as bamboo litter decomposes, resulting in the switch of microorganisms from $\mathrm{N}$ to $\mathrm{C}$ restriction. This means that microorganisms need to change their community structure in response to changes in the soil environment and relieve their own nutrient pressure. Soil bacteria rather than fungi respond significantly to both litter quality and incubation time, indicating that soil microbial composition was determined by easily decomposed substrates with a high turnover rate during the 180 days incubation. Our study highlights that the change in proportions of bamboo and broadleaved litter during bamboo expansion will affect the native microbial community structure and functional pathways of broadleaved forest soil and have important impacts on soil C sequestration and nutrient cycling. Besides the aboveground litter, roots may also affect the microbial community structure of broadleaved forest soil during bamboo expansion. 
Therefore, further consideration should be given to the effects of both root and litter, as well as the soil basic parameters, mineralogy and quality, on the microbial community.

Supplementary Materials: The following supporting information can be downloaded at: https: / / www.mdpi.com/article/10.3390/agronomy12010220/s1. Figure S1: The community composition of bacteria and fungal at the level of phylum; Figure S2: C-, N- and P-acquiring enzyme activities; Table S1: Treatment effects on soil chemical properties during the incubation.

Author Contributions: Data curation, H.D.; Formal analysis, H.D.; Investigation, H.D.; Methodology, H.D., S.S. and Q.X.; Writing—original draft, H.D.; Writing—review and editing, H.D., S.S., C.L., Q.X., J.C. and H.Q.; Formal analysis, C.L.; Funding acquisition, J.C. and H.Q.; Project administration, J.C. and H.Q.; Validation, J.C. and H.Q. All authors have read and agreed to the published version of the manuscript.

Funding: This research was funded by the National Natural Science Foundation of China (31971631, 41977083, 41671252) and the Science and Technology Department of Zhejiang Province (2021C02035).

Institutional Review Board Statement: Not applicable.

Informed Consent Statement: Not applicable.

Data Availability Statement: Not applicable.

Acknowledgments: The authors would like to thank Yingzhi Zhao and Yang Liu for the soil sample collection.

Conflicts of Interest: The authors declare that they have no known competing financial interests or personal relationships that could have appeared to influence the work reported in this paper.

\section{References}

1. Liu, R.; Zhang, Y.; Hu, X.F.; Wan, S.Z.; Wang, H.M.; Liang, C.; Chen, F.S. Litter manipulation effects on microbial communities and enzymatic activities vary with soil depth in a subtropical Chinese fir plantation. For. Ecol. Manag. 2021, 480, 118641. [CrossRef]

2. Van Der Heijden, M.G.A.; Bardgett, R.D.; Van Straalen, N.M. The unseen majority: Soil microbes as drivers of plant diversity and productivity in terrestrial ecosystems. Ecol. Lett. 2008, 11, 296-310. [CrossRef]

3. Wang, W.B.; Chen, D.S.; Sun, X.M.; Zhang, Q.; Koide, R.T.; Insam, H.; Zhang, S.G. Impacts of mixed litter on the structure and functional pathway of microbial community in litter decomposition. Appl. Soil Ecol. 2019, 144, 72-82. [CrossRef]

4. Yang, W.; Yan, Y.E.; Jiang, F.; Leng, X.; Cheng, X.L.; An, S.Q. Response of the soil microbial community composition and biomass to a short-term Spartina alterniflora invasion in a coastal wetland of eastern China. Plant Soil 2016, 408, 443-456. [CrossRef]

5. Wang, Y.J.; Liu, L.; Yang, J.F.; Duan, Y.M.; Luo, Y.; Taherzadeh, M.J.; Li, Y.F.; Li, H.K.; Awasthi, M.K.; Zhao, Z.Y. The diversity of microbial community and function varied in response to different agricultural residues composting. Sci. Total Environ. 2020, 715, 136983. [CrossRef]

6. Agnieszka, K.B.; Wojciech, B.; Edyta, S.; Agnieszka, B.; Lynn, B.; Gabriela, W. The role of plants and soil properties in the enzyme activities of substrates on hard coal mine spoil heaps. Sci. Rep. 2021, 11, 5155.

7. Bai, X.J.; Dippold, M.A.; An, S.S.; Wang, B.R.; Zhang, H.X.; Loeppmann, S. Extracellular enzyme activity and stoichiometry: The effect of soil microbial element limitation during leaf litter decomposition. Ecol. Indic. 2021, 121, 107200. [CrossRef]

8. Luan, J.W.; Li, S.Y.; Dong, W.; Liu, Y.C.; Wang, Y.; Liu, S.R. Litter decomposition affected by bamboo expansion is modulated by litter-mixing and microbial composition. Funct. Ecol. 2021, 35, 2562-2574. [CrossRef]

9. Chapman, S.K.; Newman, G.S. Biodiversity at the plant-soil interface: Microbial abundance and community structure respond to litter mixing. Oecologia 2010, 162, 763-769. [CrossRef]

10. Liu, C.C.; Liu, Y.G.; Guo, K.; Zhao, H.W.; Qiao, X.G.; Wang, S.J.; Zhang, L.; Cai, X.L. Mixing litter from deciduous and evergreen trees enhances decomposition in a subtropical karst forest in southwestern China. Soil Biol. Biochem. 2016, 101, 44-54. [CrossRef]

11. Li, H.Y.; Wei, Z.S.; Huangfu, C.H.; Chen, X.W.; Yang, D.L. Litter mixture dominated by leaf litter of the invasive species, Flaveria bidentis, accelerates decomposition and favors nitrogen release. J. Plant Res. 2017, 130, 167-180. [CrossRef]

12. Sun, H.; Wang, Q.X.; Zhang, C.G.; Li, L.; Liu, Z.B.; Liu, N.; Shao, C.; Zhang, Y.Y.; Yan, J.; Li, Y.X. Effects of different leaf litters on the physicochemical properties and soil microbial communities in Panax ginseng-growing soil. Acta Ecol. Sinica 2018, 38, 3603-3615.

13. Shiau, Y.J.; Chiu, C.Y. Changes in Soil Biochemical Properties in a Cedar Plantation Invaded by Moso Bamboo. Forests 2017, 8, 222. [CrossRef]

14. You, Y.M.; Wang, J.; Huang, X.M.; Tang, Z.X.; Liu, S.R.; Sun, O.J. Relating microbial community structure to functioning in forest soil organic carbon transformation and turnover. Ecol. Evol. 2014, 4, 633-647. [CrossRef]

15. Liu, Y.X.; Wang, S.L.; Wang, Q.K.; Zhang, J. Effects of mixed-species leaf litter on litter decomposition and soil microbial communities in experimental subtropical plantation forest. J. Food Agric. Environ. 2010, 8, 1102-1107. 
16. Pei, Z.Q.; Leppert, K.N.; Eichenberg, D.; Bruelheide, H.; Niklaus, P.A.; Buscot, F.; Gutknecht, J.L.M. Leaf litter diversity alters microbial activity, microbial abundances, and nutrient cycling in a subtropical forest ecosystem. Biogeochemistry 2017, 134, 163-181. [CrossRef]

17. Santonja, M.; Rancon, A.; Fromin, N.; Baldy, V.; Hättenschwiler, S.; Fernandez, C.; Montès, N.; Mirleau, P. Plant litter diversity increases microbial abundance, fungal diversity, and carbon and nitrogen cycling in a Mediterranean shrubland. Soil Biol. Biochem. 2017, 111, 124-134. [CrossRef]

18. Li, Y.B.; Bezemer, T.M.; Yang, J.J.; Lü, X.T.; Li, X.Y.; Liang, W.J.; Han, X.G.; Li, Q. Changes in litter quality induced by N deposition alter soil microbial communities. Soil Biol. Biochem. 2019, 130, 33-42. [CrossRef]

19. Schneider, T.; Keiblinger, K.M.; Schmid, E.; Sterflinger-Gleixner, K.; Ellersdorfer, G.; Roschitzki, B.; Richter, A.; Eberl, L.; Zechmeister-Boltenstern, S.; Riedel, K. Who is who in litter decomposition? Metaproteomics reveals major microbial players and their biogeochemical functions. ISME J. 2012, 6, 1749-1762. [CrossRef]

20. Tian, L.; Shi, W. Short-term effects of plant litter on the dynamics, amount, and stoichiometry of soil enzyme activity in agroecosystems. Eur. J. Soil Biol. 2014, 65, 23-29. [CrossRef]

21. Shi, L.; Fan, S.H.; Jiang, Z.H.; Qi, L.H.; Liu, G.L. Mixed leaf litter decomposition and N, P release with a focus on Phyllostachys edulis (Carrière) J. Houz. forest in subtropical southeastern China. Acta Soc. Bot. Pol. 2015, 84, 207-214. [CrossRef]

22. Zhao, Y.Z.; Liang, C.F.; Shao, S.; Chen, J.H.; Qin, H.; Xu, Q.F. Linkages of litter and soil C:N:P stoichiometry with soil microbial resource limitation and community structure in a subtropical broadleaf forest invaded by Moso bamboo. Plant Soil 2021, 465 , 473-490. [CrossRef]

23. Liu, J.L.; Wang, G.H.; Xu, D.M. Soil organic carbon mineralization response to litter addition in desert steppe grassland sites with differences in number of years grazing by fencing. Acta Prataculturae Sin. 2019, 28, 47-57.

24. Lu, R.K. Methods of Soil and Agro-chemical Analysis. China Agric. Science Technol. Press 2000.

25. Justine, M.F.; Yang, W.Q.; Wu, F.Z.; Tan, B.; Naeem Khan, M.; Li, Z.J. Dissolved organic matter in soils varies across a cheonsequence of Pinus massoniana plantations. Ecosphere 2017, 8, e01764. [CrossRef]

26. Lyu, M.K.; Xie, J.S.; Vadeboncoeur, M.A.; Wang, M.H.; Qiu, X.; Ren, Y.B.; Jiang, M.H.; Yang, Y.S.; Kuzyakov, Y. Simulated leaf litter addition causes opposite priming effects on natural forest and plantation soils. Biol. Fertil. Soils 2018, 54, 925-934. [CrossRef]

27. Shahzad, T.; Anwar, F.; Hussain, S.; Mahmood, F.; Arif, M.S.; Sahar, A.; Nawaz, M.F.; Perveen, N.; Sanaullah, M.; Rehman, K.; et al. Carbon dynamics in surface and deep soil in response to increasing litter addition rates in an agro-ecosystem. Geoderma 2019, 333, 1-9. [CrossRef]

28. Chen, J.H.; Chen, D.; Xu, Q.F.; Fuhrmann, J.J.; Li, L.Q.; Pan, G.X.; Li, Y.F.; Qin, H.; Liang, C.F.; Sun, X. Organic carbon quality, composition of main microbial groups, enzyme activities, and temperature sensitivity of soil respiration of an acid paddy soil treated with biochar. Biol. Fertil. Soils 2019, 55, 185-197. [CrossRef]

29. Rognes, T.; Flouri, T.; Nichols, B.; Quince, C.; Mahe, F. VSEARCH: A versatile open source tool for metagenomics. PeerJ 2016, 4, e2584. [CrossRef]

30. Koljalg, U.; Larsson, K.H.; Abarenkov, K.; Nilsson, R.H.; Alexander, I.J.; Eberhardt, U.; Erland, S.; Hoiland, K.; Kjoller, R.; Larsson, E.; et al. UNITE: A database providing web-based methods for the molecular identification of ectomycorrhizal fungi. New Phytol. 2005, 166, 1063-1068. [CrossRef]

31. Dixon, P. VEGAN, a package of R functions for community ecology. J. Veg. Sci. 2003, 14, 927-930. [CrossRef]

32. Zhang, W.W.; Lu, Z.T.; Yang, K.; Zhu, J.J. Impacts of conversion from secondary forests to larch plantations on the structure and function of microbial communities. Appl. Soil Ecol. 2017, 111, 73-83. [CrossRef]

33. Wang, Y.; Luo, X.Y.; Li, Y.C.; Chen, Z.H.; Yao, Z.X.; Fang, T.; Zhang, B.G. Effects of litter addition of Moso Bamboo (Phyllostachys edulis) and broadeaf forest on soil bacteria community. J. Agric. Biotechnol. 2020, 28, 951-962.

34. Xing, W.; Lu, X.M.; Xu, F.W.; Ying, J.Y.; Chen, D.M.; Bai, Y.F. Linking microbial community structure to carbon substrate chemistry in soils following aboveground and belowground litter additions. Appl. Soil Ecol. 2019, 141, 18-25. [CrossRef]

35. Zhang, B.B.; Wan, X.H.; Yang, J.Q.; Wang, T.; Huang, Z.Q. Effects of litters different in quality on soil microbial community structure in Cunninghamia lanceolata plantation. Acta Pedol. Sinica 2021, 58, 1040-1049. [CrossRef]

36. Dong, H.Y.; Ge, J.F.; Sun, K.; Wang, B.Z.; Xue, J.M.; Wakelin, S.A.; Wu, J.S.; Sheng, W.X.; Liang, C.F.; Xu, Q.F.; et al. Change in root-associated fungal communities affects soil enzymatic activities during Pinus massoniana forest development in subtropical China. For. Ecol. Manag. 2021, 482, 118817. [CrossRef]

37. Aragao, L.E.O.C.; Malhi, Y.; Metcalfe, D.B.; Silva-Espejo, J.E.; Jimenez, E.; Navarrete, D.; Almeida, S.; Costa, A.C.L.; Salinas, N.; Phillips, O.L.; et al. Above-and below-ground net primary productivity across ten Amazonian forests on contrasting soils. Biogeosciences 2009, 6, 2759-2778. [CrossRef]

38. Yan, J.F.; Wang, L.; Hu, Y.; Tsang, Y.F.; Wu, J.H.; Fu, X.H.; Sun, Y. Plant litter composition selects different soil microbial structures and in turn drives different litter decomposition pattern and soil carbon sequestration capability. Geoderma 2018, 319, 194-203. [CrossRef]

39. Zhang, H.C.; Yuan, W.P.; Dong, W.J.; Liu, S.G. Seasonal patterns of litterfall in forest ecosystem worldwide. Ecol. Complex. 2014, 20, 240-247. [CrossRef]

40. Wu, Z.X.; Hao, Z.P.; Sun, Y.Q.; Guo, L.P.; Huang, L.Q.; Zeng, Y.; Wang, Y.; Yang, L.; Chen, B.D. Comparison on the structure and function of the rhizosphere microbial community between healthy and root-rot Panax notoginseng. Appl. Soil Ecol. 2016, 107, 99-107. [CrossRef] 
41. Bromke, M.A. Amino Acid biosynthesis pathways in diatoms. Metabolites 2013, 3, 294-311. [CrossRef] [PubMed]

42. Rahman, M.S.; Quadir, Q.F.; Rahman, A.; Asha, M.N.; Chowdhury, A.K. Screening and characterization of phosphorus solubilizing bacteria and their effect on rice seedlings. Res. Agric. Livest. Fish. 2014, 1, 27-35. [CrossRef] 